\title{
Ground uplift detected by precise leveling in the Ontake earthquake swarm area, central Japan in 2002-2004
}

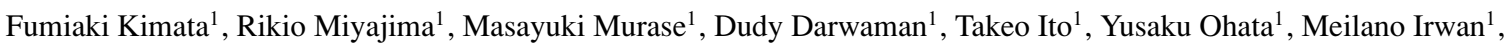 \\ Kazutomo Takano ${ }^{1}$, Fauzan Ibrahim ${ }^{1}$, Etsuro Koyama ${ }^{2}$, Hiroshi Tsuji², Teturo Takayama ${ }^{3}$, \\ Kazuya Uchida ${ }^{4}$, Jun Okada ${ }^{5}$, David Solim ${ }^{6}$, and Herri Anderson ${ }^{6}$ \\ ${ }^{1}$ Graduate School of Environmental Studies, Nagoya University, Nagoya 464-8602, Japan \\ ${ }^{2}$ Earthquake Research Institute, University of Tokyo, Tokyo 113-0032, Japan \\ ${ }^{3}$ Disaster Prevention Research Institute, Kyoto University, Uji 611-0011, Japan \\ ${ }^{4}$ Graduate School of Science, Kyushu University, Hukuoka 812-8581, Japan \\ ${ }^{5}$ Graduate School of Science, HokkaidoUniversity, Sapporo 060-0810, Japan \\ ${ }^{6}$ Department of Geodesy, Institute of Technology Bandung 40132, Indonesia
}

(Received August 7, 2004; Revised December 10, 2004; Accepted December 27, 2004)

\begin{abstract}
Repeated precise leveling in the earthquake swarm area of Ontake, central Japan has revealed uplift of 3-6 mm in proximity to the epicentral region of the most active earthquake cluster in 2002-2004. Although the uplift is small, the vertical displacement is significant even considering leveling error. This uplift is associated with increases in ${ }^{3} \mathrm{He} /{ }^{4} \mathrm{He}$ ratios and $\mathrm{CO}_{2} \delta^{13} \mathrm{C}$ values at a mineral spring in the region, indicating an upper mantle contribution. A region of low resistivity at a depth of $2 \mathrm{~km}$ beneath the uplift area has also been inferred, suggesting that the observed uplift is related to changes in a shallow seismogenic layer due to increased hydrothermal input from the earthquake swarm area.
\end{abstract}

Key words: Ground uplift, precise leveling, Ontake earthquake swarm, shallow seismogenic layer, low resistivity layer, ${ }^{3} \mathrm{He} /{ }^{4} \mathrm{He}$ ratio, $\delta^{13} \mathrm{C}, \mathrm{CO}_{2}$.

\section{Introduction}

Since 1978, earthquake swarms have been observed continuously on the east flank of the Mt. Ontake Volcano in western Nagano, Japan. During a peak in swarm activity, a phreatic explosion occurred at the Ontake volcano $7 \mathrm{~km}$ away in October 1982. The M6.8 Nagano-ken Seibu Earthquake also occurred in this region in October 1984. In 1993, the earthquake swarm migrated to the northeast (Nagoya Univ., 1999), where the swarm continues. Although the swarm involves 1000 or more earthquakes each year, only one or two of those exceed magnitude 4 in a year. The hypocenters are concentrated on the $2-6 \mathrm{~km}$ depth. (Iio et al., 1999, 2002; Horiuchi et al., 2002)

Earthquakes observed in the central mountainous and volcanic region of Japan generally occur in the shallow crust (Ito and Wada, 1995; Ito, 1999). However, the Ontake earthquake swarm is occurring in an even shallower part of the crust, indicating the presence of increased geothermal activity in the shallow crust of this mountainous and volcanic region.

Takahata et al. (2003) have measured the chemical compositions of hot and mineral springs in the region of the earthquake swarm since the 1984 Naganoken-Seibu Earthquake.

After the source region of the Ontake swarm earthquakes moves around the Shirakawa mineral spring from southeast-

Copy right (C) The Society of Geomagnetism and Earth, Planetary and Space Sciences (SGEPSS); The Seismological Society of Japan; The Volcanological Society of Japan; The Geodetic Society of Japan; The Japanese Society for Planetary Sciences; TERRAPUB ern flank of Mt. Ontake in 1993, the increase in the ${ }^{3} \mathrm{He} /{ }^{4} \mathrm{He}$ ratio and $\delta^{13} \mathrm{C}$ values of $\mathrm{CO}_{2}$ is observed at the Shirakawa mineral spring in 1996.

As a part of the surveillance of the seismic and volcanic activity in this region, our group has conducted precise leveling every year since 1999 in order to identify possible ground deformation (Kimata and Miyajima, 2001; Kimata et al., 2003). This paper reports the detection of ground uplift in 2003 and discusses its cause and implications.

\section{Precise Leveling and Detected Ground Uplift}

Figure 1 shows the location of precise leveling routes and the epicentral distribution of earthquakes in the periods April 2002-April 2003 and May 2003-March 2004. Hypocenters were determined using data recorded by the seismic observation network of the Japan Meteorological Agency (JMA). In 1999, leveling along the route from Agematsu to Otaki started, and the route was later extended to Yashikino to cross the area of earthquake swarms in April 2002, and then to Kaida in April 2004. Benchmarks were established every 100 to $700 \mathrm{~m}$ along the leveling route.

Precise leveling was conducted using digital levels (Ni002s, Carl Zeiss) with super-invar rods. The measurement threshold was $2.5 \times L[\mathrm{~km}]^{1 / 2} \mathrm{~mm}$ throughout the leveling exercise, where $L$ is the distance in kilometers between benchmarks. The cumulative height difference along the leveling route is $350 \mathrm{~m}$.

The vertical movement along the Agematsu-MitakeYashikino leveling route and a profile of the leveling route are shown in Fig. 2. The heights at BM34 located in the 

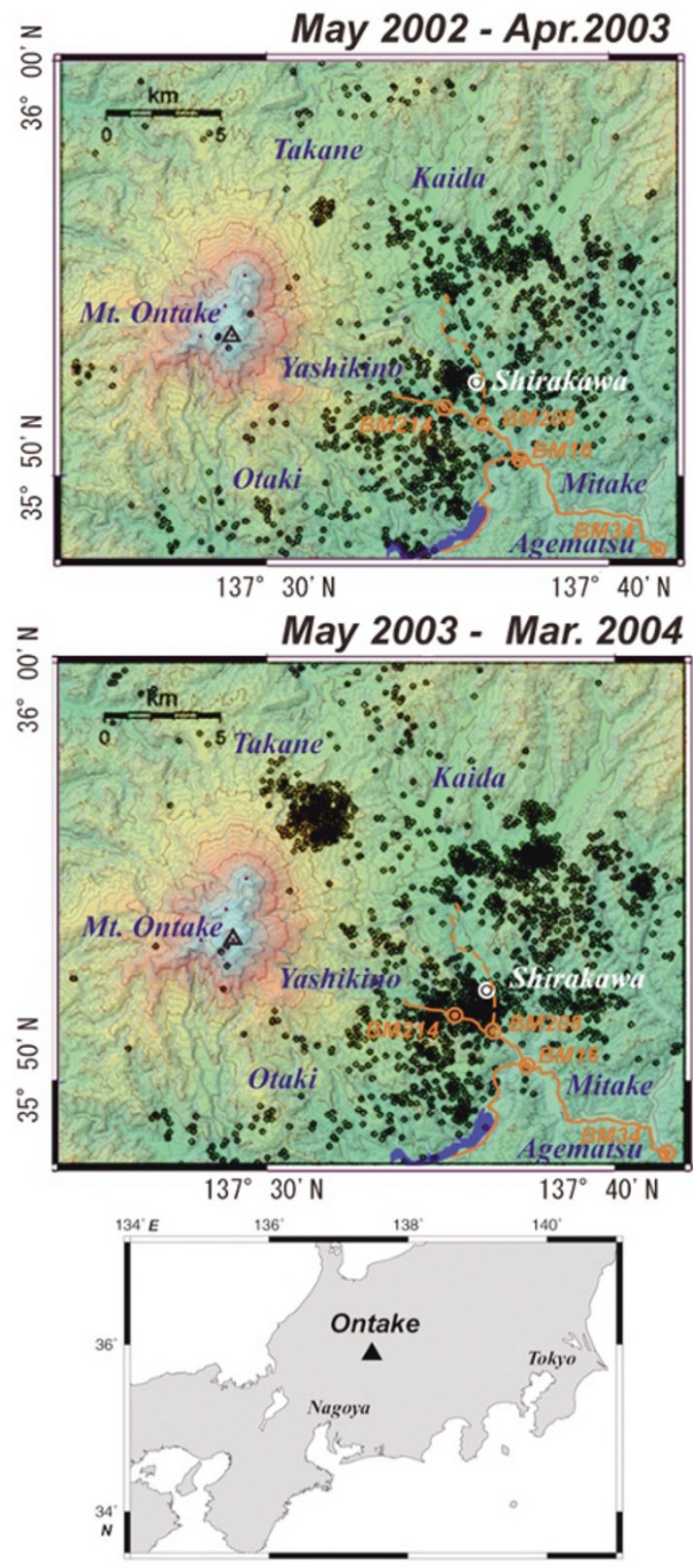

Fig. 1. Location map of leveling routes on the east flank of the Mt Ontake Volcano, and the hypocenter distribution of earthquakes in April 2002-April 2003 and May 2003-March 2004. The locations of BM16, 34, 208 and 214, and the Shirakawa spring are also shown. Broken lines indicate the leveling route constructed in April 2004. Earthquake hypocenters were determined from JMA, NIED, and university data.

eastern part of the leveling route are fixed constant throughout the period 1999-2004. At some bench marks, subsidence considered to be under the influence of differential settlement of a structure was observed. Comparing with vertical movements at the adjoining bench marks, this subsidence shows large movements amounting to $10 \mathrm{~mm}$ over five years since 1999. The movements at benchmarks exhibiting such disturbances are indicated by open symbols in Fig. 2 and are excluded from the present discussion.

Although a leveling loop is usually made to check survey error, the leveling route could not be closed in this survey. However, as shown in Fig. 2, the vertical displacements de-

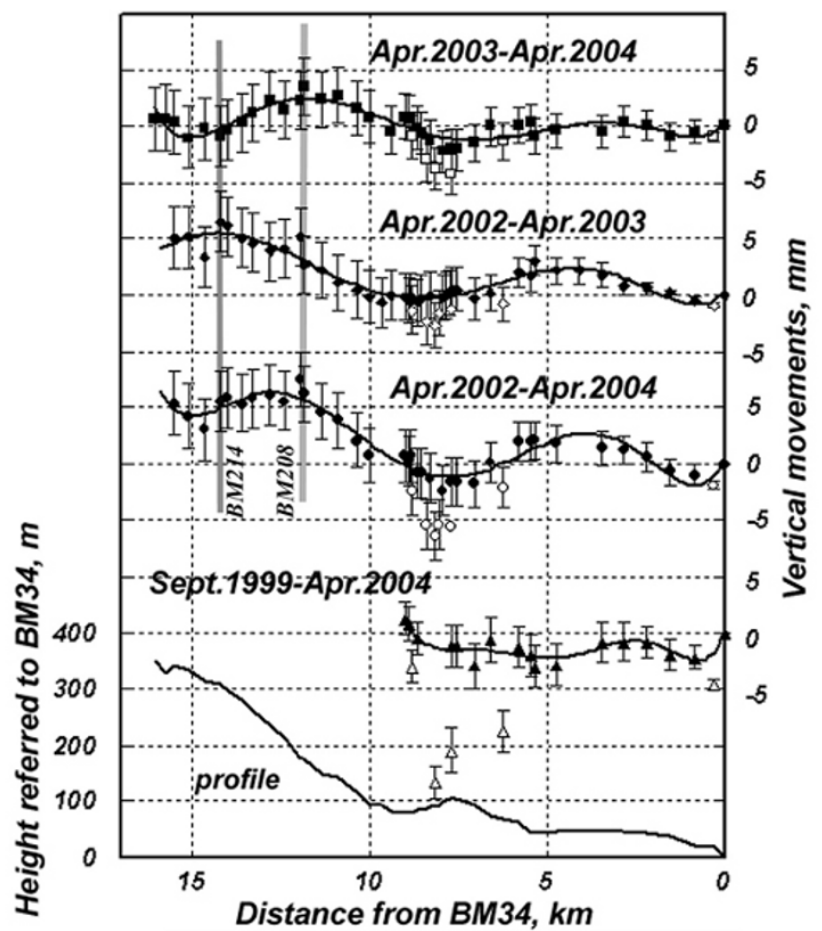

Fig. 2. Vertical movements along the leveling route detected by precise leveling in the period September 1999-April 2004. BM34 did not move throughout the survey period. Open symbols indicate the movements at disturbed benchmarks (excluded from discussion).

tected by leveling display no correlation with the profile of the leveling route, suggesting that the vertical deformation is not caused by leveling error generally.

Figure 3(a) shows the closure errors of leveling between adjoining benchmarks in 1999, 2002, 2003, and 2004. Closure errors are within $\pm 1.0 \times L[\mathrm{~km}]^{1 / 2} \mathrm{~mm}$. The leveling error $\delta(h)$ for a non-loop leveling route is given by (Pelton and Smith, 1982)

$$
\delta(h)=(\beta / \sqrt{j}) \sqrt{L}
$$

where $\delta(h)$ is in millimeters, $\beta$ is a constant, $j$ is the temporal number of measurements, and $L$ is a distance in kilometers from the reference benchmark. From leveling at the Long Valley Caldera, USA, the value of $\beta$ is calculated to be 0.7 (Howle et al., 2003). The leveling error $\delta(h)$ can also be calculated by

$$
\delta(h)=\sum(\delta h)^{2}
$$

where $\delta h$ is the measurement thresholds between benchmarks. The values of $\delta(h)$ for benchmarks along the leveling route in 1999, 2002, 2003 and 2004 are shown in Fig. 3(b). The curve of Eq. (1) using $\beta=0.7$ is also shown for comparison. The present results match the curve well. The leveling error at the western terminal benchmark, $17 \mathrm{~km}$ from BM219, is about $2 \mathrm{~mm}$.

Assuming this survey error, the error of detected vertical change can also be calculated from the survey error in two leveling runs, as follows.

$$
\delta(h)=\sqrt{\left(\delta_{1}(h)^{2}+\delta_{2}(h)^{2}\right)}
$$





Fig. 3. Measurement error of precise leveling. (a) Closure errors of leveling between adjoining benchmarks. (b) Integration error along the leveling route from BM34 in 1999, 2002, 2003 and 2004. (c) Relationship between vertical movement and relative height at benchmarks in reference to BM34 in the period 2002-2004.

The errors of vertical movement calculated using this equation are indicated by error bars in Fig. 2 .

The scale error of the leveling survey is closely correlated with the benchmark profile. Figure 3(c) shows the correlation between the vertical movements in 2002-2004 and benchmark height in reference to BM34 on the east end of the leveling route. A positive correlation is evident among vertical movements and heights referred to BM34. The correlation is approximately linear, with a coefficient of $20.7 \times 10^{-6}$. However, the ground deformation detected is much larger than the scale error. The residual of estimation exceeds $3 \mathrm{~mm}$ at BM208.

The effect of lake water weight in Lake Ontake, located adjacent to the Mitake-Otaki leveling route (Fig. 1) should also be considered. The impoundment volume of the lake changes due to flushing of the Makio Dam. The vertical deformation caused by lake loading change was estimated using the viscous model of Haskell (1936). The vertical movements calculated during periods of full flushing and $50 \%$ flushing differ by less than $1 \mathrm{~mm}$ on the AgematsuMitake-Yashikino leveling route. Thus, the effect of lake loading is not considered in this paper.

Ground uplift amounting to a peak of $6 \mathrm{~mm}$ was detected at BM214 in 2002-2003, and $3 \mathrm{~mm}$ displacement was detected at BM208 in 2003-2004. Figure 4 shows the $2 \mathrm{~mm}$ vertical movement counters in these three periods of 20022003, 2003-2004 and 2002-2004. Four M4 earthquakes occurred in the earthquake swarm area between April 2002 and March 2004, three of which occurred near the MitakeYashikino leveling route, as indicated by the stars in Fig. 4. The epicenters of these earthquakes were within $1 \mathrm{~km}$ of the leveling route. From Fig. 4, the ground uplift was detected in the region closest to the epicenters of the M4 earthquakes in 2002-2004, although there is some discrepancy in the timing. The ground uplift in 2003-2004 occurred 1-2 km southeast of the uplift in 2002-2003.

\section{Discussion}

The point pressure sources are estimated from the ground uplift detected by precise leveling using the Mogi solution (Mogi, 1958). As benchmarks are arranged almost linearly, the point pressure source is assumed to be located beneath

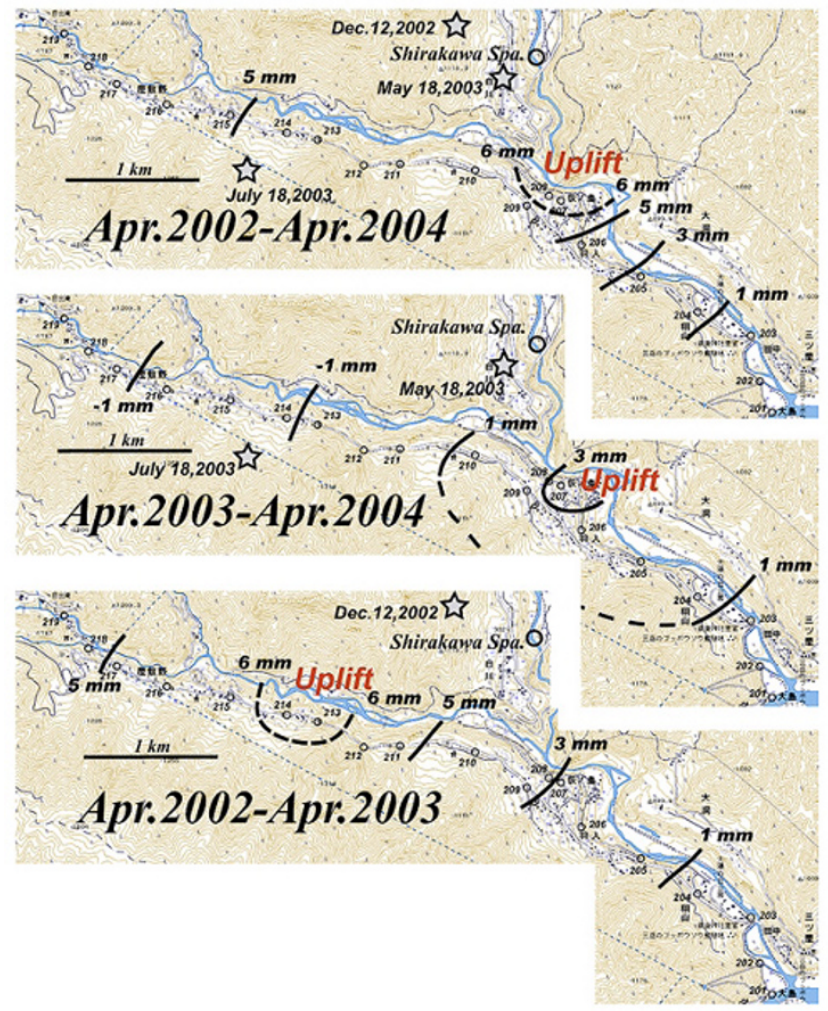

Fig. 4. Vertical movement counters along the northern part of the Agematsu-Mitake-Yashikino leveling route in the period April 2002-April 2004. Counter lines indicate deformation in $2 \mathrm{~mm}$ intervals. The hypocentral locations of M4 earthquake that occurred on December 12, 2002, May 18, 2003 and July 18, 2003, and the location of the Shirakawa spring are also shown. (Upper) April 2002-April 2004. (Middle) April 2003-April 2004. (Lower) April 2002-April 2003.

the benchmark for which the maximum uplift was detected. Point pressure sources with volumes of $(2-4) \times 10^{5} \mathrm{~m}^{3}$ are estimated to be inflated at a depth of about $2-3 \mathrm{~km}$. As the benchmarks that exhibited uplift are located approximately $1000 \mathrm{~m}$ above sea level, inflation occurs at depths of about 1-2 $\mathrm{km}$ below sea level.

A number of features may be related to the observed uplift. A shallow seismogenic zone at a depth of about $6 \mathrm{~km}$ has 
been suggested for the southern part of the Ontake area by Iio et al. (1999, 2002) due to increased heat flow (Ito, 1999; Tanaka and Ito, 2002). Tanaka and Ito (2002) suggested that the temperatures in the zone may exceed $200-300^{\circ} \mathrm{C}$. Furthermore, earthquakes of M4.2, 4.5 and 3.9 occurred within $1-2 \mathrm{~km}$ of the uplifted benchmarks on December 12, 2002, May 18, 2003, and July 18, 2003, respectively (Fig. 4). The seismic cluster including these large earthquakes was one of the most active swarms in the period 2002-2003.

A low-resistivity region at a depth of $2 \mathrm{~km}$ beneath the uplift area has also been inferred from specific electric conductivity measurements in the Ontake earthquake swarm area by Kasaya et al. (2002). The resistivity index is lower than $100 \Omega / \mathrm{m}$, suggesting the presence of a hydrothermal chamber rather than magma.

Finally, an anomalous increase in $\delta^{13} \mathrm{C}$ of $\mathrm{CO}_{2}$ and ${ }^{3} \mathrm{He} /{ }^{4} \mathrm{He}$ ratios was observed at the Shirakawa spring near the region of uplift (Takahata et al., 2003) based on analyses of 23 gas samples from hot and mineral springs in the earthquake swarm area from June 1996 to June 2000. These anomalies were detected following the migration of the earthquake swarm to the northeast. These changes have been explained by a model with three end-members, mantle, limestone and sediment. Geochemical studies have generally indicated input from a mantle source in this uplift region (Takahata et al., 2003).

From satisfaction of seismic observation network such as HINET (High Sensitivity Seismograph Network Japan), the seismic activity around $15 \mathrm{~km}$-depth is observed also in the earthquake group area recently (Aoki, H., personal communication). Since supply of the gas from deep crust and the seismic activity in the deep crust are estimated, the upheaval detected by our leveling, which is depended on energy supply from the deep crust to the pressure source in upper crust.

Ground uplifts amounting to $10-100 \mathrm{~cm}$ have already been detected in association with the earthquake swarms at large calderas such as Long Valley (Hill et al., 2003) and Campi Flegrei, Italy (Orsi et al., 1999). The intensity of the earthquake swarm in Ontake area is so low that that the maximum magnitude of earthquakes if approximately 4 and ground uplift is only 3-7 mm. It should, however, be noted that the uplift in the earthquake swarm area infers point pressure source in the shallow seismogenic layer and is associated with a region of low resistivity $(<100 \Omega / \mathrm{m})$ and anomalous increases in $\delta^{13} \mathrm{C}$ of $\mathrm{CO}_{2}$ and ${ }^{3} \mathrm{He} /{ }^{4} \mathrm{He}$ ratios, suggesting potential shallow hydrothermal activity.

\section{Conclusion}

Precise leveling across the earthquake swarm area on the east flank of the Mt. Ontake volcano in central Japan has been conducted periodically since 1999 . The leveling surveys have detected uplifts of $3-6 \mathrm{~mm}$ in proximity to the most active cluster of earthquakes in 2002-2004. The uplift of $6 \mathrm{~mm}$ represents significant ground deformation through the discussion of leveling error. Assume a point pressure source beneath the leveling route, inflation is estimated to be in progress at a depth of only $2-3 \mathrm{~km}$ and to be increasing in volume, currently at $5 \times 10^{5} \mathrm{~m}^{3}$. This uplift is also as- sociated with a region of low resistivity at a depth of $2 \mathrm{~km}$ and anomalous increases in $\delta^{13} \mathrm{C}$ of $\mathrm{CO}_{2}$, indicating the presence of mantle-derived gas. Thus, the present results indicate an increase in geothermal activity and hydrothermal pressure from the deeper crust.

\section{References}

Haskell, N. A., The motion of a viscous fluid under a surface load, Physics, 6, 265-269, 1936.

Hill, P. D., J. O. Langbein, S. Prejean, Relations between seismicity and deformation during unrest in Long Valley Caldera, California, from 1995 through 1999, J. Volcanol. Geotherm. Res., 127, 175-193, 2003.

Horiuchi, S., K. Takai, Y. Iio, and S. Zheng, High sampling frequency seismic array at Ootaki, Nagano Prefecture: Stress drop distribution and seismic velocity change, Proceedings of the International Workshop on Physics of Active Fault, 2002.

Howle, J. F.,J. O. Langbein, C. D. Farrar, and S. K. Wilkinson, Deformation near the Casa Diablo geothermal well field and related processes Long Valley caldera, Eastern California, 1993-2000, J. Volcanol. Geotherm. Res., 127, 365-390, 2003.

Iio, Y., S. Ohmi, R. Ikeda, E. Yamamoto, H. Ito, H. Sato, Y. Kuwahara, T. Ohminato, B. Shibazaki, and M. Ando, Slow initial phase generated by micro-earthquakes occurring in the Western Nagano Prefecture, Japan: the source effect, Geophys. Res. Lett, 26, 1969-1972, 1999.

Iio, Y., S. Horiuchi, K. Yamamoto, Y. Kobayashi, S. Ohmi, R. Ikeda, E. Yamamoto, H. Sato, and H. Ito, Three- dimensional $\mathrm{P}$ and $\mathrm{S}$ wave velocity structures in the aftershock area of the 1984 Western Nagano prefecture, Japan Earthquake: Implications for the relationship between structures and earthquake occurrences, Proceedings of the International Workshop on Physics of Active Fault, 2002.

Ito, K., Seismogenic layer, reflective lower crust, surface heat flow and large inland earthquakes, Tectonophysics, 306, 423-433, 1999.

Ito, K. and H. Wada, Geo-thermal structure and seismic activity beneath Hida Mountai region, Monthly Earth, 18, 123-128, 1995 (in Japanese).

Kasaya, T., N. Oshiman, N. Sumitomo, M. Uyeshima, Y. Iio, and D. Uehara, Resistivity structure around hypocental area of the 1984 Nagano Prefecture earthquake in central Japan, Earth Planets Space, 54, 107-118, 2002.

Kimata, F. and R. Miyajima, Ground deformation detected by precise leveling around Ontake earthquake swarm area in September 1999 to April 2000, Bulletin of Tono Earthquake Science Institute, 6, 91-96, 2001 (in Japanese).

Kimata, F., R. Miyajima, M. Murase, M. Irwan, D. Darmawan, D. Solim, and Y. Ohta, Vertical movements detected by precise leveling at the Ontake earthquake swarm area in the period of 1999-2003: Upheaval at Yashikino Area, Bulletin of Tono Earthquake Science Institute, 10, 6975, 2003 (in Japanese).

Mogi, K., Relation between the eruptions of various volcanoes and the deformations of the ground surfaces around them, Bull. Earthq. Res. Inst. Tokyo, 36, 99-134, 1958.

Nagoya University, Temporal variations of seismic activity in the southeastern Ontake volcano (1977-1998), Report of the Coordinating Community for Volcano Eruption Prediction, 74, 64-68, 1999 (in Japanese).

Orsi, G., L. Civetta, C. D. Gaudio, S. Vitta, M. A. Vito, R. Isaia, S. M. Petrazzuoli, G. P. Ricciardic, and C. Ricco, Short-term ground deformations and seismicity in the resurgent Campi Flegrei caldera (Italy): an example of active block-resurgence in a densely populated area, J. Volcanol. Geotherm. Res., 91, 415-451, 1999.

Pelton, J. R. and R. B. Smith, Contemporary vertical surface displacements in Yellowstone National Park, J. Geophys. Res., 87, 2745-2761, 1982.

Takahata, N., R. Yokochi, Y. Nishio, and Y. Sano, Volatile element isotope systematics at Ontake volcano, Jpn, Geochem. J., 37, 299-310, 2003.

Tanaka, A. and H. Ito, Temperature at base of the seismogenic zone and its relationship to the focal depth of Western Nagano Prefecture area, $J$. Seism. Soc. Jpn., 55, 1-10, 2002 (in Japanese).

F. Kimata (e-mail: kimata@seis.nagoya-u.ac.jp), R. Miyajima, M. Murase, D. Darwaman, T. Ito, Y. Ohata, M. Irwan, K. Takano, F. Ibrahim, E. Koyama, H. Tsuji, T. Takayama, K. Uchida, J. Okada, D. Solim, and H. Anderson 